\title{
ARTICLES
}

\section{FEMUR SHAFT FRACTURES (BROKEN THIGHBONE) AN OVERVIEW}

Ms. Kammu Verma* | Dr. Krishna Chauhan**

*Ph.D. Scholar, Himalayan University, Arunachal Pradesh, India. \& Lecturer, Rattan Professional Education College, Sohana, Mohali, Punjab, India.

**Principal, Shimla Nursing College, Annadale, Shimla, Himachal Pradesh, India. DOI: http://doi.org/10.47211/trr.2020.v06i01.002

Received $10^{\text {th }}$ May 2020, Accepted $22^{\text {nd }}$ May 2020, Available online $25^{\text {th }}$ June 2020.

\section{ABSTRACT}

Femoral shaft fractures are common, especially in high-energy trauma, with an incidence of around 4 per 10000 person-years. The femur is the longest bone in the body and a highly vascularised bone, due to its role in hematopoiesis. The bone is supplied by penetrating branches of the profunda femoris artery; therefore large volumes of blood (up to $1500 \mathrm{ml}$ ) can be lost when fractured. In all groups, the injury may be open or associated with neurovascular injury. ${ }^{1}$

Most femoral shaft fractures require surgery to heal. It is unusual for femoral shaft fractures to be treated without surgery. Very young children are sometimes treated with a cast.Most femur fractures are fixed within 24 to 48 hours. Sometimes it will be delayed until other life-threatening injuries or unstable medical conditions are stabilized. To reduce the risk of infection, open fractures are treated with antibiotics as soon as you arrive at the hospital. The open wound, tissues, and bone will be cleaned during surgery. For the time between initial emergency care and your surgery, your doctor may place your leg either in a long-leg splint or in traction. This is to keep your broken bones as aligned as possible and to maintain the length of your leg.Skeletal traction is a pulley system of weights and counterweights that holds the broken pieces of bone together. It keeps your leg straight and often helps to relieve pain ${ }^{2}$

Key words: femur shaft fracture, trauma.

\section{About Authors}

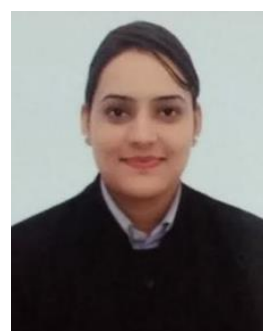

Author Ms. Kammu Verma is Ph. D. Scholar in Himalayan University, Arunachal Pradesh, India. She is working as Lecturer in Rattan Professional Education College, Sohana, Mohali, Punjab, India.

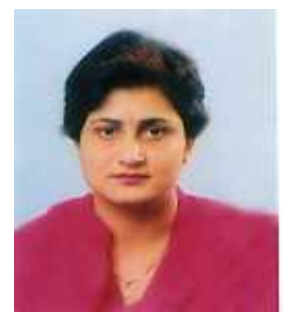

Author Dr. Krishna Chauhan is Principal in Shimla Nursing College, Annadale, Shimla, Himachal Pradesh, India. 


\section{ARTICLES}

\section{EPIDEMIOLOGY:}

- The highest age- gender- specific incidence of femoral shaft fracture is seen in males from 15 to 24 years of age and in females 75 years of age or older.

- Femoral shaft fractures occur most frequently in young men after high-energy trauma and elderly women after a low-energy fall.

- The bimodal distribution peaks at 25 and 65 years of age with an overall incidence of approximately 10 per 10,0000 population per year. ${ }^{3}$

DEFINITION: The long, straight part of the femur is called the femoral shaft. When there is a break anywhere along this length of bone, it is called a femoral shaft fracture. This type of broken leg almost always requires surgery to heal. ${ }^{4}$

\section{MACHANISM OF INJURY:}

- Femoral shaft fracture in adults is almost always the result of high-energy trauma. These fractures results from motor vehicle accidents, gunshot injuries, or fall from a height.

- Pathological fractures, especially in the elderly, commonly occur at the relatively weak metaphysicaldiaphyseal junction. Any fracture that is inconsistent with the degree of trauma should arouse suspicion for pathologic fracture.

- Stress fractures occur mainly in military recruits or runners. Most patients reports a recent increase in training intensity just before the onset of high pain. ${ }^{5}$

\section{CLASSIFICATION OF FEMUR SHAFT FRACTURE:}

The Winquist classification of femoral shaft fractures is based on fracture comminution and was proposed by Winquist in 1980.

This classification is used with regards to management decision making, in determining whether a fracture requires an intramedullary nail or open reduction.

Type 0: no comminution or a small butterfly fragment less than $25 \%$ of the width of the bone

Type I: small butterfly fragment less than $25 \%$ of the width of the bone

Type II: butterfly fragment $50 \%$ or less of the width of the bone

Type III: comminuted with a large butterfly fragment, greater than $50 \%$ of the width of the bone.

Type IV: severe comminution of an entire segment of bone (segmental comminution) ${ }^{6}$

This classification is for the severity of the fracture.

Type 1: Stress Fracture

A stress fracture is a small crack in the bone. Stress fractures often develop from overuse, such as from high-impact sports. Most stress fractures occur in the weight-bearing bones. A stress fracture is an overuse injury. When muscles are overtired, they are no longer able to lessen the shock of repeated impacts. When this happens, the muscles transfer the stress to the bones. This can create small cracks or fractures. 


\section{ARTICLES}

\section{Type 2: Severe Impaction Fractures}

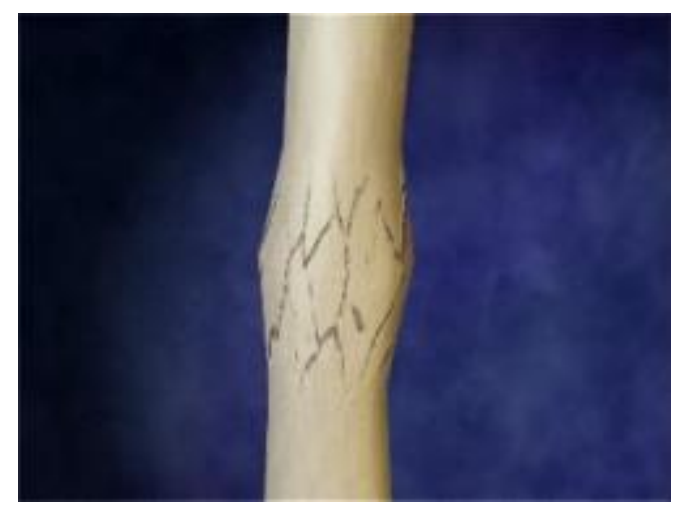

An impacted fracture is a fracture in which the bone breaks into multiple fragments, which are driven into each other. It is a closed fracture that occurs when pressure is applied to both ends of the bone, causing it to split into two fragments that jam into each other.

\section{Type 3: Partial Fractures}

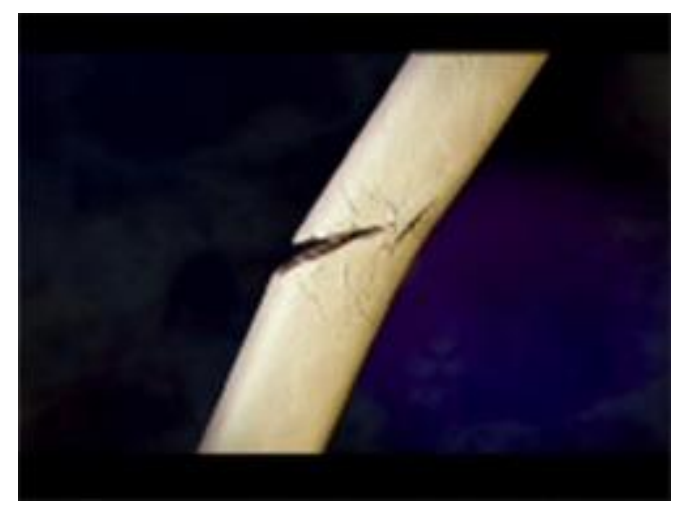

A partial fracture is an incomplete break of a bone. This type of fracture refers to the way the bone breaks. In an incomplete fracture the bone cracks but doesn't break all the way through. In contrast there is the complete fracture, where the bone snaps into two or more parts.

\section{Type 4: Complete Displaced Fracture}

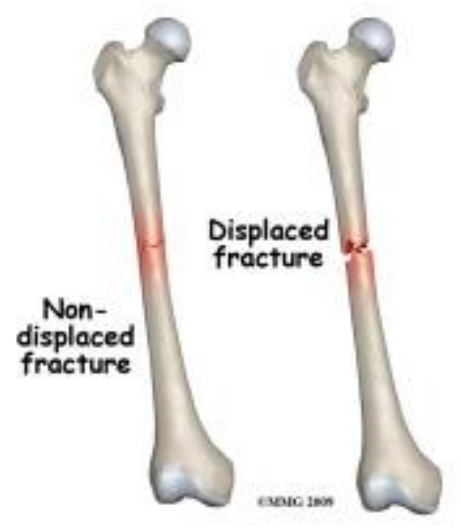




\section{ARTICLES}

A bone has a displaced fracture when it breaks in two or more pieces and is no longer correctly aligned. Displacement of fractures is defined in terms of the abnormal position of the distal fracture fragment in relation to the proximal bone. ${ }^{7}$

\section{CLIINICAL FEATURES:}

A femoral shaft fracture usually causes immediate, severe pain. You will not be able to put weight on the injured leg, and it may look deformed-shorter than the other leg and no longer straight. ${ }^{4}$

\section{DIAGNOSTIC EVALUATION:}

\section{Medical history and physical examination:}

It is important that your doctor know the specifics of how you hurt your leg. For example, if you were in a car accident, it would help your doctor to know how fast you were going, whether you were the driver or a passenger, whether you were wearing your seat belt, and if the airbags went off. This information will help your doctor determine how you were hurt and whether you may be hurt somewhere else.

It is also important for your doctor to know if you have any other health conditions, such as high blood pressure, diabetes, asthma, or allergies. Your doctor will also ask you if you use tobacco products or are taking any medications.

After discussing your injury and medical history, your doctor will do a careful examination. He or she will assess your overall condition, and then focus on your leg. Your doctor will look for:

- An obvious deformity of the thigh/leg (an unusual angle, twisting, or shortening of the leg)

- Breaks in the skin

- $\quad$ Bruises

- Bony pieces that may be pushing on the skin

After the visual inspection, your doctor will feel along your thigh, leg, and foot looking for abnormalities and checking the tightness of the skin and muscles around your thigh. He or she will also feel for pulses. If you are awake, your doctor will test for sensation and movement in your leg and foot.

\section{Imaging Tests:}

Imaging tests will provide your doctor with more information about your injury.

$\mathbf{X}$-rays. The most common way to evaluate a fracture is with $\mathbf{x}$-rays, which provide clear images of bone. X-rays can show whether a bone is intact or broken. They can also show the type of fracture and where it is located within the femur. 


\section{ARTICLES}

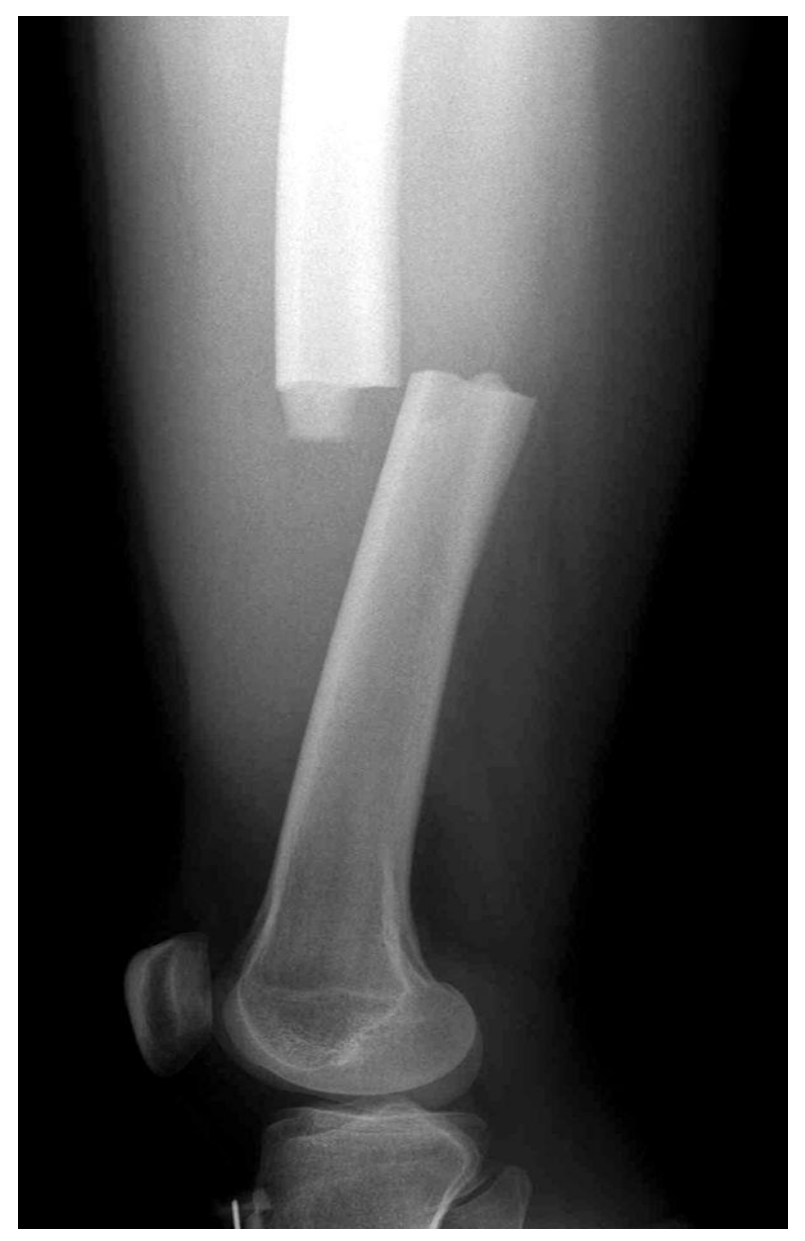

X-ray shows a transverse fracture of the femur. The break is a straight horizontal line across the shaft.

Computerized tomography (CT) scans: If your doctor still needs more information after reviewing your x-rays, he or she may order a CT scan. A CT scan shows a cross-sectional image of your limb. It can provide your doctor with valuable information about the severity of the fracture. For example, sometimes the fracture lines can be very thin and hard to see on an x-ray. A CT scan can help your doctor see the lines more clearly. ${ }^{4}$

\section{TREATMENT:}

Skeletal traction is a pulley system of weights and counterweights that holds the broken pieces of bone together. It keeps your leg straight and often helps to relieve pain. 


\section{ARTICLES}

\section{External fixation:}

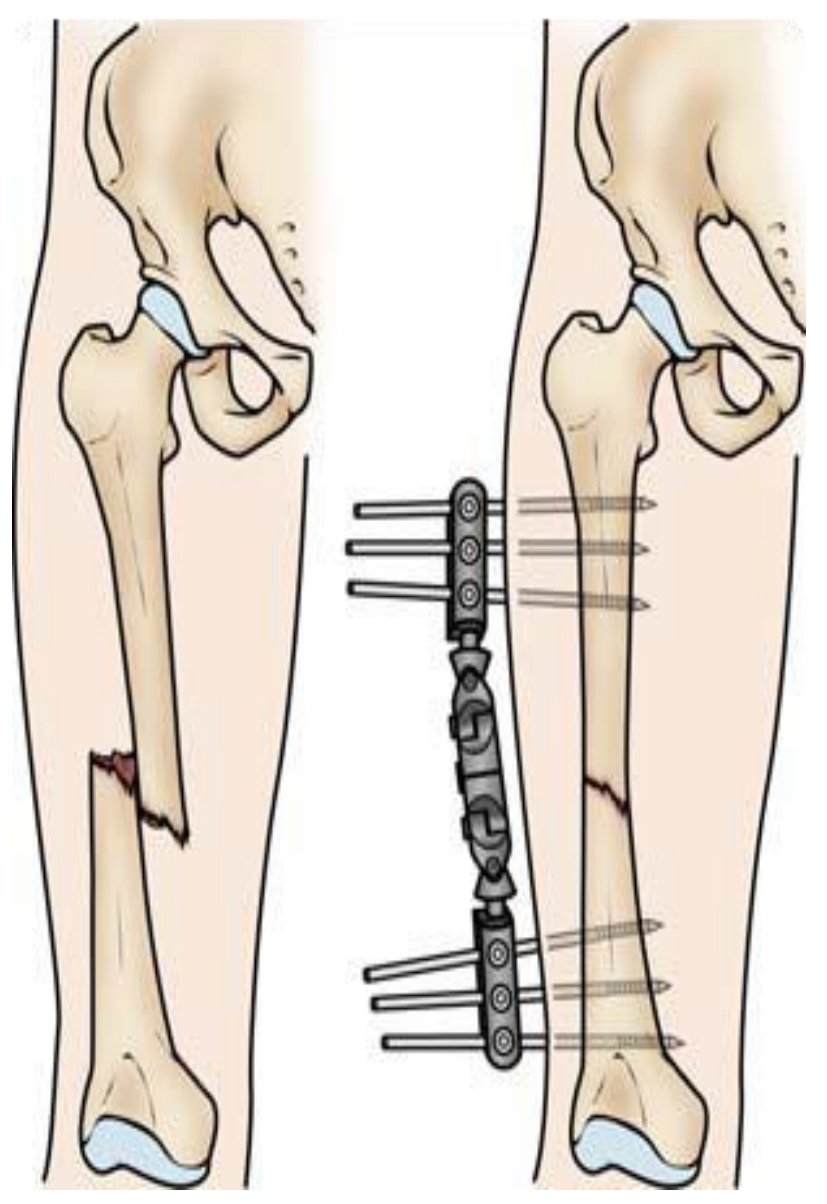

External fixation is often used to hold the bones together temporarily when the skin and muscles have been injured.

In this type of operation, metal pins or screws are placed into the bone above and below the fracture site. The pins and screws are attached to a bar outside the skin. This device is a stabilizing frame that holds the bones in the proper position.

External fixation is usually a temporary treatment for femur fractures. Because they are easily applied, external fixators are often put on when a patient has multiple injuries and is not yet ready for a longer surgery to fix the fracture. An external fixator provides good, temporary stability until the patient is healthy enough for the final surgery. In some cases, an external fixator is left on until the femur is fully healed, but this is not common. 


\section{ARTICLES}

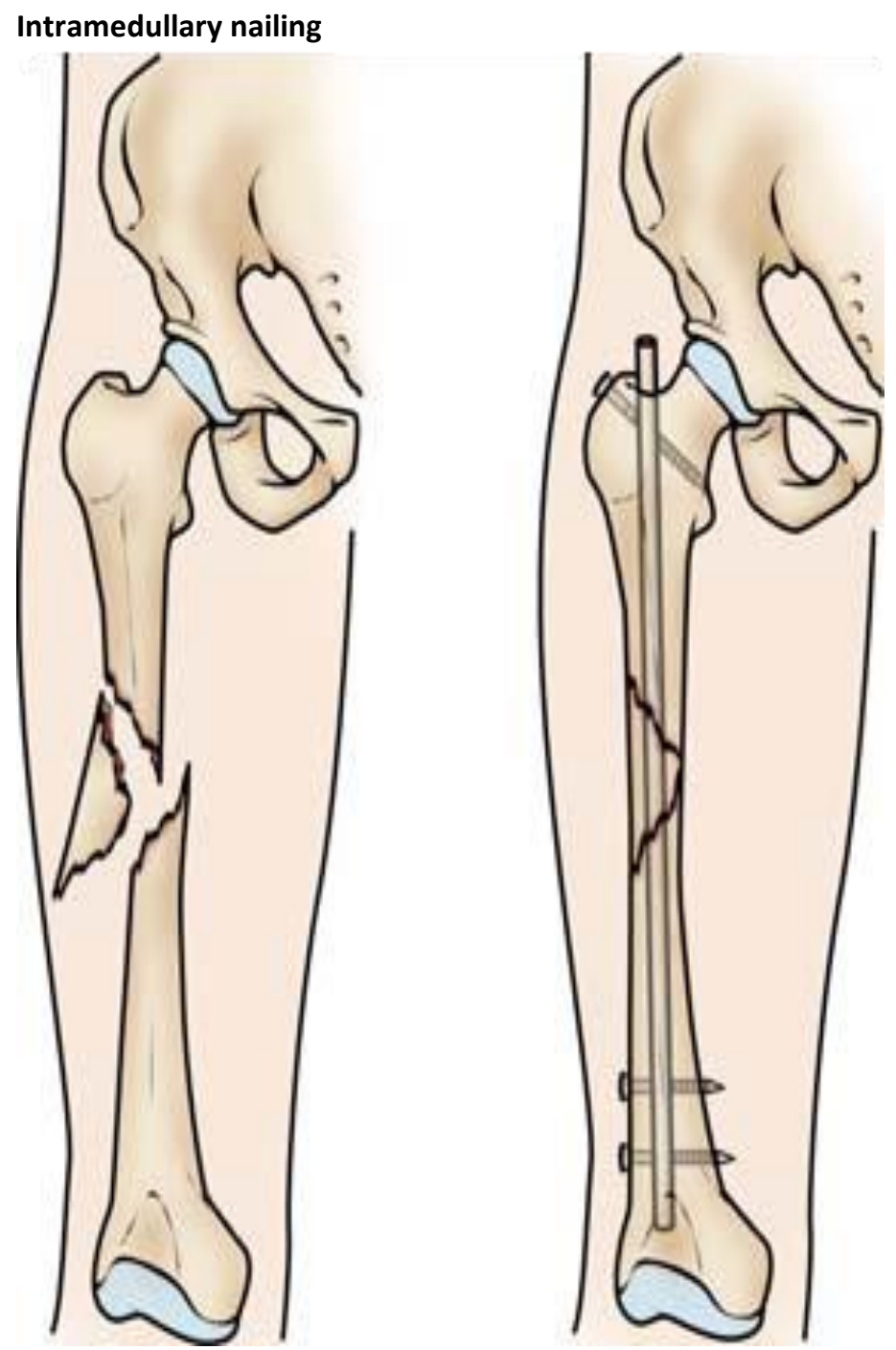

Currently, the method most surgeons use for treating femoral shaft fractures is intramedullary nailing. During this procedure, a specially designed metal rod is inserted into the canal of the femur. The rod passes across the fracture to keep it in position.

An intramedullary nail can be inserted into the canal either at the hip or the knee. Screws are placed above and below the fracture to hold the leg in correct alignment while the bone heals. 


\section{ARTICLES}

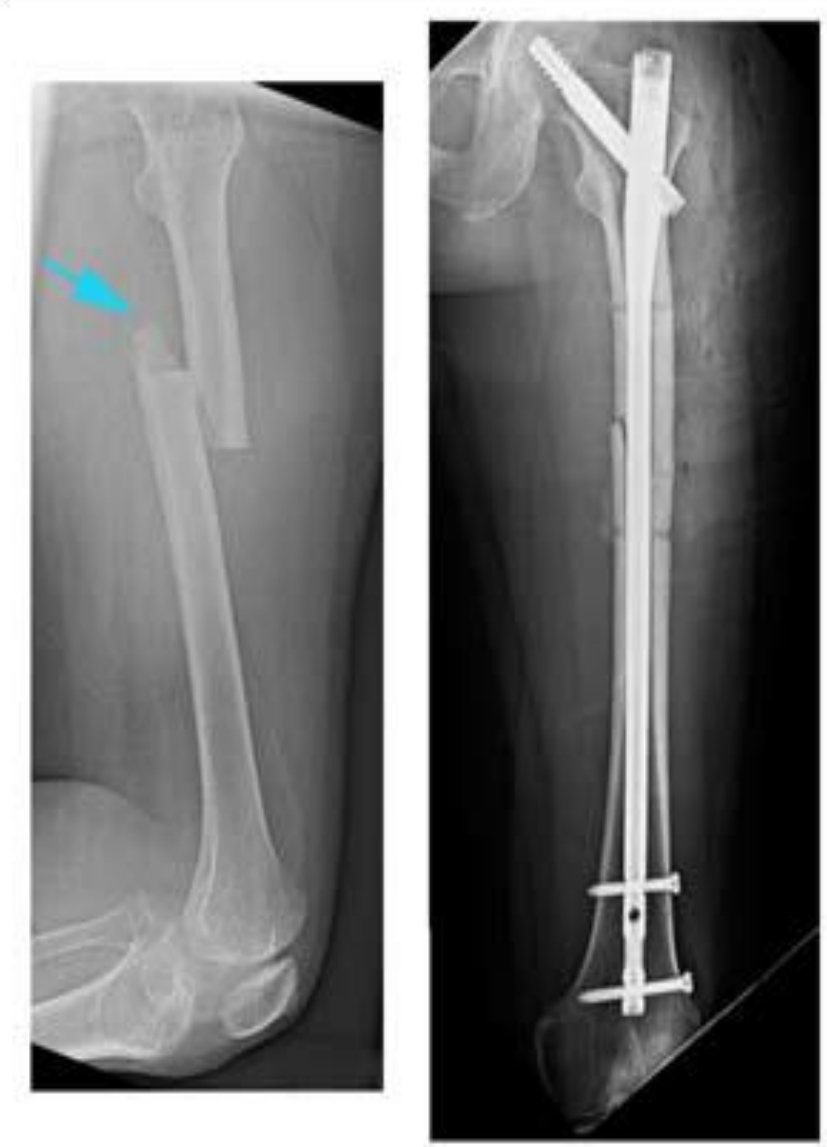

(Left) This x-ray, taken from the side, shows a transverse fracture of the femur. (Right) In this front view $x$-ray, the fracture has been treated with intramedullary nailing

Intramedullary nails are usually made of titanium. They come in various lengths and diameters to fit most femur bones.

\section{Plates and screws}

During this surgery, the bone fragments are first repositioned into their normal alignment. They are held together with screws and metal plates attached to the outer surface of the bone.

Plates and screws are often used when intramedullary nailing may not be possible, such as for fractures that extend into either the hip or knee joints.

\section{What is recovery from a femur shaft fracture like?}

Most femoral shaft fractures take 3 to 6 months to completely heal. Some take even longer, especially if the fracture was open or broken into several pieces or if the patient uses tobacco products.

\section{Pain Management}

Pain after an injury or surgery is a natural part of the healing process. Your doctor and nurses will work to reduce your pain, which can help you recover faster. Medications are often prescribed for short-term pain relief after surgery or an injury. Many types of medications are available to help manage pain. These include acetaminophen, 


\section{ARTICLES}

nonsteroidal anti-inflammatory drugs (NSAIDs), gabapentinoids, muscle relaxants, opioids, and topical pain medications. Your doctor may use a combination of these medications to help control pain, as well as minimize the need for opioids. Some pain medications may have side effects that can impact your ability to drive and do other activities. Your doctor will talk to you about the side effects of your pain medications.

\section{Weight bearing}

Many doctors encourage leg motion early on in the recovery period. It is very important to follow your doctor's instructions for putting weight on your injured leg to avoid problems.

In some cases, doctors will allow patients to put as much weight as possible on the leg right after surgery. However, you may not be able to put full weight on your leg until the fracture has started to heal. Be sure to follow your doctor's instructions carefully.

When you begin walking, you will probably need to use crutches or a walker for support.

\section{Physical Therapy}

Because you will most likely lose muscle strength in the injured area, exercises during the healing process are important. Physical therapy will help to restore normal muscle strength, joint motion, and flexibility. It can also help you manage your pain after surgery.

A physical therapist will most likely begin teaching you specific exercises while you are still in the hospital. The therapist will also help you learn how to use crutches or a walker. ${ }^{4}$

\section{REHABILITATION:}

- Early patient mobilization out of bed is recommended.

- Early range of knee motion is indicated.

- Weight bearing on the extremity is guided by a number of factors including the patients associated injuries, soft tissue status, type of implant, and the location of the fracture.

\section{COMPLICATION:}

- Nerve injury: This is uncommon because of the femoral and sciatic nerve is encased in muscle throughout the length of the thigh. Most injuries occur as a result of traction or compression during surgery.

- Vascular injury: This may result from tethering of the femoral artery at the adductor hiatus.

- Compartment syndrome: This occurs only with significant bleeding .It presents as a pain out of proportion, tense thigh swelling numbness to medial thigh or painful passive quadriceps stretch.

- Infection: The risk is greater with open versus closed IM nailing. Type 1,2 and 3a open fracture carry a low risk infection with IM nailing whereas fracture with gross contamination, exposed bone, and extensive soft tissue injury have a higher risk of infection regardless of treatment method.

- Refracture: Patients are vulnerable during early callus formation and after hardware removal. It is usually associated with plate or external fixation.

- Fixation device failure: This results from nonunion or " cycling" of device especially with plate fixation. ${ }^{8}$ 


\section{ARTICLES}

\section{REFEERENCES:}

1. Teach Me Surgery. Femoral Shaft Fracture - Fixation - Complications - Teachmesurgery. [online] Available at: <https://teachmesurgery.com/orthopaedic/hip/femoral-shaft-fracture/> [Accessed 29 April 2020].

2. Trauma and fracture surgery b. Femur Shaft Fracture Treatment [Internet]. Boston Medical Center. 2020 [cited 3o April 2020]. Available from: https://www.bmc.org/trauma-and-fracture-surgery/femurshaft/treatment.

3. Kenneth A.egol, Kenneth J. Koval,JosephD.Zuckerman Handbook of fracture $.5^{\text {th }}$ ed.Wolters Kluwer 2015: 372.

4. Femur Shaft Fractures (Broken Thighbone) - Ortholnfo - AAOS [Internet]. Orthoinfo.aaos.org. [cited 30 April 2020]. Available from: https://orthoinfo.aaos.org/en/diseases--conditions/femur-shaft-fracturesbroken-thighbone.

5. Kenneth A.egol, Kenneth J. Koval, JosephD.Zuckerman Handbook of fracture $.5^{\text {th }}$ ed. Wolters Kluwer 2015: 374.

6. S.T. Hansen jr W. femoral shaft fracture [Internet]. Science.gov. 1980 [cited 30 April 2020]. Available from: http:// radiopaedia.org.

7. pedia p. Physiopedia - universal access to physiotherapy and physical therapy knowledge [Internet]. Physio-pedia.com. [cited 30 April 2020]. Available from: https://www.physio-pedia.com.

8. Kenneth A.egol, Kenneth J. Koval,JosephD.Zuckerman Handbook of fracture $.5^{\text {th }}$ ed. Wolters Kluwer 2015: 380-381. 